\section{Commentary: Good things come to those who wait}

Thin X. Vo, MD, and

Fraser D. Rubens, MD, MSc, FACS, FRCSC

In this issue of The Journal, Kunioka and colleagues ${ }^{1}$ provide justification for the "five-minute test" (FMT) to reduce the incidence of re-exploration for bleeding after cardiac surgery. It is well established that re-exploration for bleeding portends significantly worse outcomes after cardiac surgery. ${ }^{2}$ Hence, interventions to reduce reexploration for bleeding are valuable. Although the study by Kunioka and colleagues suffers from the limitations and biases of a retrospective cohort study, their results are worth sharing due to the sheer simplicity of the FMT.

The FMT is simple, yet effective. Re-exploration for bleeding was $1.5 \%$ in the FMT group versus $5.7 \%$ in the non-FMT group. FMT was also correlated with decreased postoperative bleeding (1440 mL vs $1165 \mathrm{~mL})$.

Three caveats should be considered. First, important outcomes such as blood transfusions and mortality were not different between the 2 groups. Second, since the study occurred after the implementation of the FMT on an institutional basis, it is highly possible that surgeons were generally more careful since their results were now being measured, ie, "Hawthorne effect." Finally, the decision to re-explore for bleeding is instution and surgeon dependent, and these results may not be replicated at other institutions.

Intestingly, addition of the FMT did not significantly add to the length of time between weaning from cardiopulmonary bypass and chest closure, indicating that the FMT perhaps removed some uncertainty regarding bleeding and chest closure.

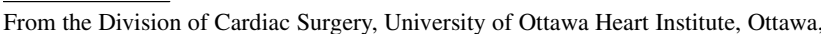
Ontario, Canada.

Disclosures: The authors reported no conflicts of interest.

The Journal policy requires editors and reviewers to disclose conflicts of interest and to decline handling or reviewing manuscripts for which they may have a conflict of interest. The editors and reviewers of this article have no conflicts of interest.

Received for publication Aug 30, 2021; revisions received Aug 30, 2021; accepted for publication Sept 2, 2021; available ahead of print Sept 7, 2021

Address for reprints: Fraser D. Rubens, MD, MSc, FACS, FRCSC, University of Ottawa Heart Institute, 40 Ruskin St, Ottawa, Ontario, K1Y 4W7, Canada (E-mail: frubens@ottawaheart.ca)

JTCVS Techniques 2022;12:131

2666-2507

Copyright (c) 2021 The Author(s). Published by Elsevier Inc. on behalf of The American Association for Thoracic Surgery. This is an open access article under the CC BY-NC-ND license (http://creativecommons.org/licenses/by-nc-nd/4.0/).

https://doi.org/10.1016/j.xjtc.2021.09.005
}

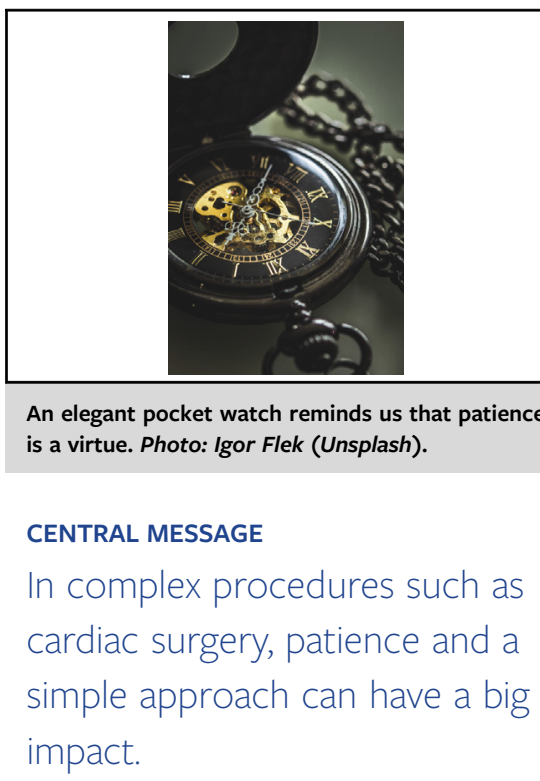

This study by Kunioka colleagues highlights that patience and simplicity can go a long way. The FMT is a simple, reproducible, objective, and systematic intervention. Due to the retrospective study design, we cannot say with great certainty that the FMT itself is responsible for the decrease in re-exploration for bleeding. Then again, perhaps it does not matter what mechanism is responsible for these findings. The FMT forces the surgeon to systematically dedicate at least 5 minutes to hemostasis. It also forces the surgeon to be a bit more careful. Incorporation of FMT into an algorithm or checklist can further automate the hemostatic process. ${ }^{3}$ This is especially valuable when teaching trainees, as reproducibility, consistency, and simplicity are principles to impart on our residents as they progress through their own mental checklists and develop routines. Ultimately, FMT reminds us that providing better and safer care can be as simple as taking a "coffee break" for 5 minutes.

\section{References}

1. Kunioka S, Shirasaka T, Narita M, Shibagaki K, Kikuchi Y, Saijo Y, Kamiya H Five-minute test to prevent postcardiotomy reexploration. J Thorac Cardiovasc Surg Tech. 2022;12:121-9.

2. Ruel M, Chan V, Boodhwani M, McDonald B, Ni X, Gill G, et al. How detrimental is reexploration for bleeding after cardiac surgery? J Thorac Cardiovasc Surg. 2017; 154:927-35

3. Van Boxtel AGM, Van Veghel D, Hamad MAS, Schulz DN, Stepaniak PS, Van Straten AHM. Use of an intraoperative checklist to decrease the incidence of re-exploration for postoperative bleeding after cardiac surgery. Interact Cardiovasc Thorac Surg. 2017;25:555-8. 